\title{
BMJ Open Evaluation of compliance with early postbirth follow-up and unnecessary visits to the paediatric emergency department: a prospective observational study at the Lenval Children's Hospital in Nice
}

Antoine Tran (D) , ${ }^{1,2,3}$ Anne-Laure Hérissé, ${ }^{1}$ Marion Isoardo, ${ }^{1}$ Petri Valo, ${ }^{1,4}$ Anne-Marie Maillotte, ${ }^{5}$ Hervé Haas, ${ }^{1,6}$ Dominique Donzeau, ${ }^{7}$ Emma Freyssinet, ${ }^{1}$ Christian Pradier, ${ }^{2,8}$ Stéphanie Gentile (1) ${ }^{3}$

To cite: Tran A, Hérissé A-L, Isoardo $\mathrm{M}$, et al. Evaluation of compliance with early postbirth follow-up and unnecessary visits to the paediatric emergency department: a prospective observational study at the Lenval Children's Hospital in Nice. BMJ Open 2022;12:e056476. doi:10.1136/ bmjopen-2021-056476

- Prepublication history and additional supplemental material for this paper are available online. To view these files, please visit the journal online (http://dx.doi.org/10.1136/ bmjopen-2021-056476)

Received 16 August 2021 Accepted 13 December 2021

D) Check for updates

(c) Author(s) (or their employer(s)) 2022. Re-use permitted under CC BY-NC. No commercial re-use. See rights and permissions. Published by BMJ.

For numbered affiliations see end of article.

Correspondence to Dr Antoine Tran; tran.a@pediatrie-chulenvalnice.fr

\section{ABSTRACT}

Objective To evaluate compliance with the French National Authority for Health's (Haute Autorité de Santé, HAS) postbirth follow-up recommendations for newborns attending our paediatric emergency department (PED) and identify risk factors associated with non-compliance and unnecessary emergency department utilisation.

Design Prospective, single centre.

Setting Fourth biggest PED in France in terms of attendance (CHU-Lenval).

Patients 280 patients of whom 249 were included in the statistical analysis.

Main outcome measures The primary outcome of this study was the evaluation of compliance of the care pathway for newborns consulting at the PED with respect to the French postbirth follow-up recommendations. Secondary outcome was the assessment of whether the visit to the PED was justified by means of PED reception software and two postconsultation interviews

Results $77.5 \%$ (193) of the newborns had non-compliant care pathways and $43 \%$ (107) of PED visits were unnecessary. Risk factors associated with a non-compliance regarding the HAS's postbirth follow-up recommendations were: unnecessary visit to the PED (OR 2.0, 95\% $\mathrm{Cl} 1.1$ to 3.9), precariousness (OR 2.8, $95 \% \mathrm{Cl} 1.4$ to 6.2 ), birth in a public maternity hospital (OR 2.5, $95 \% \mathrm{Cl} 1.3$ to 4.8 ) and no information about HAS's postbirth follow-up recommendations on discharge from maternity ward (OR 11.4, 95\% $\mathrm{Cl} 5.8$ to 23.3). Risk factors for unnecessary PED visits were: non-compliant care pathway (OR $2.0,95 \% \mathrm{Cl} 1.1$ to 3.9 ) and a first medical visit at a PED (OR $1.8,95 \% \mathrm{Cl} 1.1$ to 3.1).

Conclusion Postbirth follow-up may lead to decrease unnecessary emergency department visits unnecessary emergency department visits.

Trial registration number The study bears the clinical trial number NCT02863627.

\section{INTRODUCTION}

Newborns attending an emergency department (ED) represent a public health concern. For example, overall in the USA, $7.7 \%$ of
Strengths and limitations of this study

- This is the first study to analyse the care pathway for newborn visits to a paediatric emergency department.

- This was a single-centre study with a relatively small sample size limiting applicability in general population.

- The absence of a control group did not allow comparison of compliance and non-compliance with the French National Authority for Health's postbirth follow-up recommendations.

Our analysis did not reach the target sample size.

children are taken to an ED during their first month of life. ${ }^{1}$ An identical rate was found in a study conducted in Northern Ireland. ${ }^{2}$

In the Paediatric Hospitals of Nice University Hospital Centre (CHU-Lenval) (France), newborns represented $1.4 \%$ (811 newborns) of visits to the paediatric ED (PED) in 2016. This prevalence is constant (806 newborns or $1.4 \%$ of visits in 2015). However, most of the reasons for the visits are related to childcare and could be managed upstream by a general practitioner. The number of real newborn emergencies after discharge from the maternity ward are scarce. ${ }^{2}$ An unpublished pilot study, carried out in 2001 at Lenval Paediatric Emergencies (Nice, France), showed that almost $50 \%$ of the consultations were resolved by simple childcare advice.

Previous studies ${ }^{2-5}$ have shown that a diagnosis of a 'healthy newborn' is retained in $10 \%-34 \%$ of newborn visits to the PED, and that the visit is unnecessary in $45 \%-52 \%$ of cases. ${ }^{6-8}$ Therefore, a large part of the consultations would fall within the scope of work of a general practitioner. Meara et al showed 


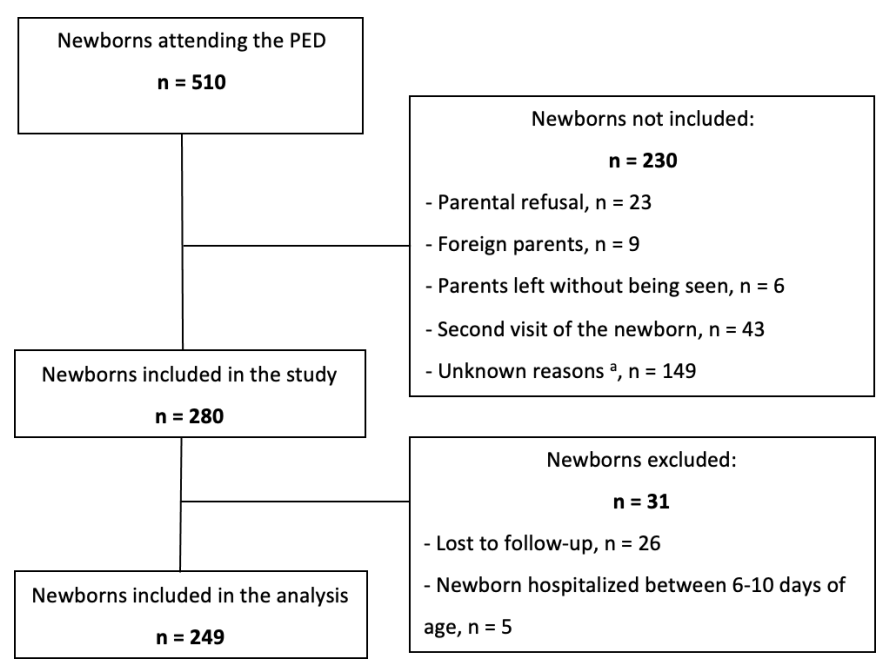

Figure 1 Patient flow chart. a The reasons why eligible children were not included were probably related to workload and the organisation of medical and paramedical teams. $P E D$, paediatric emergency department.

that a follow-up programme after early discharge from the maternity ward reduced the rate of newborn attendance at a PED within 21 days by $10 \%$.

In Europe, the postdischarge follow-up of newborns differs from country to country. In France, before 2014, data from the French national perinatal survey revealed significant differences in care both for postpartum women and their newborns, in terms of length of stay in the maternity ward and the offer of medical follow-up on discharge. This report highlights differences in follow-up mainly related to the characteristics of the place of delivery. Ideally, the length of stay should take into account the availability of out-of-hospital resources ensuring a suitable follow-up for both newborns and their mothers on discharge. ${ }^{1011}$

Following an increase in early maternity ward discharges, the French National Authority for Health (Haute Autorité de Santé (HAS)) published a report in 2014 to suggest a care framework for newborns. ${ }^{12}$ The new recommendations include a medical visit to a paediatrician (or a general practitioner with an expertise in newborn follow-up) between 6 and 10 days of age. However, barriers to applying the framework include differences in care networks throughout France with follow-up being provided by various health professionals on discharge such as physicians (paediatricians or not), midwives, paediatric nurses or the Maternal and Child Healthcare Service. To facilitate application of the recommendations, the regional network of prenatal care of Nice (Mediterranean network) introduced an information sheet into the children's health booklets (which is kept by the parents and updated at each medical consultation) in April 2016 (online supplemental appendix 1). This sheet includes a reminder that the first medical visit after discharge from the maternity ward should take place at age $6-10$ days, and outlines symptoms which require urgent medical consultation. ${ }^{13}$ However, there are no studies concerning the impact of these new recommendations on the inappropriate use of PED during the first month of life.

The main objective of this study was to evaluate compliance with the HAS's postbirth follow-up recommendations for newborns attending our PED. The secondary objectives were to evaluate whether the PED visit was justified and then to estimate the risk factors associated with a non-compliance according to the HAS recommendations and/or inappropriate use of the PED.

\section{METHODS}

\section{Design}

This was a prospective study conducted in the PED of the CHU-Lenval in Nice, France. This PED is the fourth largest in France in terms of attendance (59010 admissions in 2016) and is the only University Hospital Department of Paediatric Emergencies in the Alpes-Maritimes and Var departments in the southeast of France.

\section{Participants}

The sample size was calculated based on a preliminary retrospective evaluation of the care pathway of 94 newborns who had attended the PED. With a $10 \%$ margin and absolute accuracy of $5 \%$, the number of participants needed was 280 . The participants were included by the attending paediatrician during their visit to the PED. The data were collected using the PED software 'Terminal Urgences'. To gather follow-up data, the parents were contacted twice after the PED visit. The inclusion period was 4 July 2016 to 6 January 2017. Inclusion criteria were the following: any newborn attending the PED of the University Hospital Centre (CHU)-Lenval Children's Hospital, affiliated to the French healthcare system, and for whom both parents signed a non-objection form. The only non-inclusion criterion was parental refusal.

\section{Primary and secondary endpoints}

The primary endpoint was assessment of the compliance or non-compliance with the national guidelines of the care pathway for the follow-up of newborns consulting at the PED. The newborn's care pathway was defined as compliant if the recommended HAS medical consultation had been carried out with a paediatrician (or a general practitioner) between 6 and 10 days of age.

The secondary endpoints included assessment of whether the visit to the PED was justified. According to previous studies, only $10 \%-37 \%$ of newborns are referred to a PED by a health professional. ${ }^{235}$ Additional examinations (blood tests, imaging, etc) are carried out for $32 \%-44 \%^{3514}$ and newborns are hospitalised in $13 \%-47 \%$ of cases. ${ }^{23514}$ These three last criteria can be used to define whether the PED visit is necessary or not. As a result, we used the following definitions: PED visit was justified if the newborn was referred by a health professional, and/or additional examinations were carried out during the PED visit, and/or the newborn was 
Table 1 Characteristics of the newborns

\begin{tabular}{|c|c|c|}
\hline & $\mathbf{N}$ & \\
\hline Newborn & 249 & \\
\hline Gender (girl) & & $124(49.8 \%)(95 \% \mathrm{Cl} 43.4$ to 46.2$)$ \\
\hline Prematurity ${ }^{\star}$ & & $8(3.2 \%)(95 \% \mathrm{Cl} 0.0$ to 0.1$)$ \\
\hline $\begin{array}{l}\text { Low birth } \\
\text { weight }<2.5 \mathrm{~kg}\end{array}$ & & 5 (2.0\%) (95\% Cl 0.7 to 4.6$)$ \\
\hline Vaginal Delivery & & 197 (79.1\%) (95\% Cl 73.5 to 84.0$)$ \\
\hline Maternity ward & 249 & \\
\hline Private maternity & & $120(48.2 \%)(95 \% \mathrm{Cl} 41.8$ to 54.6$)$ \\
\hline Public maternity & & $117(47.0 \%)(95 \% \mathrm{Cl} 40.7$ to 53.4$)$ \\
\hline Other maternity & & $12(4.8 \%)(95 \% \mathrm{Cl} 2.5$ to 8.3$)$ \\
\hline $\begin{array}{l}\text { Early discharge from } \\
\text { maternity } \dagger\end{array}$ & & 33 (13.3\%) (95\% Cl 9.3 to 18.1$)$ \\
\hline $\begin{array}{l}\text { Type of newborn } \\
\text { feeding }\end{array}$ & 249 & \\
\hline Formula feeding & & $100(40.1 \%)(95 \% \mathrm{Cl} 34.0$ to 46.5$)$ \\
\hline Breast feeding & & 95 (38.2\%) (95\% Cl 32.1 to 44.5$)$ \\
\hline Mixed feeding & & $54(21.7 \%)(95 \% \mathrm{Cl} 16.7$ to 27.3$)$ \\
\hline \multicolumn{3}{|l|}{ Parents } \\
\hline Both parents & 249 & \\
\hline First-time parents & & $125(50.2 \%)(95 \% \mathrm{Cl} 43.8$ to 56.6$)$ \\
\hline Precariousness $\ddagger$ & & 83 (33.3\%) (95\% Cl 27.5 to 39.6$)$ \\
\hline Mother & 249 & \\
\hline Age (years) & & $30.1(5.7) / 30.0$ (25.0 to 35.0$)$ \\
\hline $\begin{array}{l}\text { French language } \\
\text { speaker }\end{array}$ & & 232 (93.2\%) (95\% Cl 89.3 to 96.0$)$ \\
\hline Job-seeker§ & & 107 (43.0\%) (95\% Cl 0.4 to 49.4$)$ \\
\hline Father & 245 & \\
\hline Age (years) & & $34.0(7.4) / 33.0$ (29.0 to 38.0$)$ \\
\hline $\begin{array}{l}\text { French language } \\
\text { speaker }\end{array}$ & & 238 (97.1\%) (95\% Cl 94.2 to 98.8$)$ \\
\hline Job-seeker§ & & 26 (10.6\%) (95\% Cl 7.1 to 15.2$)$ \\
\hline
\end{tabular}

Values presented as $\mathrm{n}(\%)(95 \% \mathrm{Cl})$, mean (SD), median (Q1; Q3).

*Prematurity: $<37$ weeks of pregnancy.

$\dagger$ Early discharge: discharge from the maternity ward $<3$ days if vaginal delivery, $<4$ days if caesarean.

tPrecariousness: EPICES score $>30$.

§Job-seeker: socioprofessional group 8 (from INSEE, https://www. insee.fr).

EPICES, Assessment score of Precariousness and Health Inequalities for the Centres of Health Examinations.

subsequently hospitalised. Additional examinations were defined as any use of resources that are not commonly available by healthcare providers outside the hospital: point-of-care testing (quick blood test), ECG, blood test, urinalysis, imaging, hospitalisation regardless of the duration and/or reason.

Risk factors associated with a non-compliance according to the HAS recommendations and/or an unnecessary visit to the PED were: the clinical and demographic characteristics of the newborn, the parents' social characteristics (profession classified according to the Socio-Professional Classification of the National Institute of Statistics and
Table 2 Description of the newborn care pathways

\begin{tabular}{|c|c|c|}
\hline & n & \\
\hline Non-compliant care pathway & 249 & $193(77.5 \%)(\mathrm{Cl} 95=71.1$ to 82.5$)$ \\
\hline $\begin{array}{l}\text { Parental information at the } \\
\text { maternity ward } \dagger\end{array}$ & 249 & \\
\hline Have been informed correctly & & $68(27.3 \%)(\mathrm{Cl} 95=21.9$ to 33.3$)$ \\
\hline Have been informed incorrectly & & $125(50.2 \%)(\mathrm{Cl} 95=43.8$ to 56.6$)$ \\
\hline Have not been informed & & $56(22.5 \%)(\mathrm{Cl} 95=17.5$ to 28.2$)$ \\
\hline First medical visit & 249 & \\
\hline Age (days) & & $16.4(7.0) / 16.0$ (10.0 to 21.0$)$ \\
\hline With a private paediatrician & & $153(61.5 \%)(\mathrm{Cl} 95=55.1$ to 67.5$)$ \\
\hline With a general practitioner & & $31(12.5 \%)(\mathrm{Cl} 95=8.6$ to 17.2$)$ \\
\hline With a paediatrician at a $\mathrm{MCHC}$ & & $10(4.0 \%)(\mathrm{Cl} 95=1.9$ to 47.3$)$ \\
\hline
\end{tabular}

\begin{tabular}{|c|c|}
\hline $\begin{array}{l}\text { Medical visit during the first } \\
\text { month of age }\end{array}$ & \\
\hline With a private paediatrician & $163(65.5 \%)(\mathrm{Cl} 95=59.2$ to 71.4$)$ \\
\hline $\begin{array}{l}\text { Age at the first medical visit } \\
\text { (days) }\end{array}$ & $16.6(7.2) / 16.0$ (10.0 to 21.0$)$ \\
\hline No of medical visits & $1.5(0.8) / 1.0$ (1.0 to 2.0$)$ \\
\hline With a general practitioner & $35(14.1 \%)(\mathrm{Cl} 95=10.0$ to 19.0$)$ \\
\hline $\begin{array}{l}\text { Age at the first medical visit } \\
\text { (days) }\end{array}$ & $17.1(7.1) / 16.0$ (10.5 to 23.0$)$ \\
\hline No of medical visits & $1.2(0.4) / 1.0(1.0$ to 1.0$)$ \\
\hline $\begin{array}{l}\text { With a paediatrician at the } \mathrm{MCHC} \\
\text { services }\end{array}$ & $11(4.4 \%)(\mathrm{Cl} 95=2.2$ to 7.8$)$ \\
\hline $\begin{array}{l}\text { Age at the first medical visit } \\
\text { (days) }\end{array}$ & 20.8 (7.2) / 21.0 (19.0 to 25.5) \\
\hline No of medical visits & $1.0(0) / 1.0(1.0$ to 1.0$)$ \\
\hline With a midwife & $173(69.5 \%)(\mathrm{Cl} 95=63.4$ to 75.1$)$ \\
\hline $\begin{array}{l}\text { Age at the first medical visit } \\
\text { (days) }\end{array}$ & 5.7 (2.2) / 5.0 (4.0 to 7.0$)$ \\
\hline No of medical visits & 2.0 (0.9) / 2.0 (1.0 to 2.0$)$ \\
\hline $\begin{array}{l}\text { With a nurse at the } \mathrm{MCHC} \\
\text { services }\end{array}$ & $68(27.3 \%)(\mathrm{Cl} 95=21.9$ to 33.3$)$ \\
\hline $\begin{array}{l}\text { Age at the first medical visit } \\
\text { (days) }\end{array}$ & $13.3(6.1) / 12.0$ (9.0 to 16.3$)$ \\
\hline No of medical visits & 2.1 (1.2) / 2.0 (1.0 to 3.0) \\
\hline No medical follow-up & 55 (22.1\%) (Cl95=17.1 to 27.2$)$ \\
\hline $\begin{array}{l}\text { No follow-up (paramedical, } \\
\text { medical) }\end{array}$ & $9(3.6 \%)(\mathrm{Cl} 95=1.7$ to 6.8$)$ \\
\hline
\end{tabular}

Values a presented as $\mathrm{n}(\%)(95 \% \mathrm{Cl})$, mean (SD), median (Q1; Q3).

*Non-compliant care pathway: the medical consultation with a paediatrician (or a general practitioner) not carried out between 6 and 10 days of age according the HAS recommendations.

tParents informed at the maternity ward concerning the HAS recommendations. $\ddagger \mathrm{MCHC}$ : maternal and child healthcare.

HAS, Haute Autorité de Santé.

Economic Studies; precariousness assessed by the Assessment score of Precariousness and Health Inequalities for the Centres of Health Examinations (EPICES) (defined as precarious if EPICES score $>30),{ }^{15}$ the use of resources during the PED visit, the newborn's care pathway during the first month of life, the information provided to parents in the maternity ward concerning the date of the first medical consultation after discharge and the symptoms requiring an emergency medical consultation. 
Table 3 Details of consultations at the paediatric emergency department

\begin{tabular}{|c|c|c|}
\hline & $\mathbf{n}$ & \\
\hline PED consultation & 249 & \\
\hline Age (days) & & $16.4(6.9) / 17.0$ (11.0 to 22.0$)$ \\
\hline $\begin{array}{l}\text { Patient not referred by a } \\
\text { physician }\end{array}$ & & $\begin{array}{l}175(70.37 \%)(\mathrm{Cl} 95=64.2 \text { to } \\
75.9)\end{array}$ \\
\hline On-call care services ${ }^{\star}$ & & $\begin{array}{l}149(59.8 \%)(C \mid 95=53.5 \text { to } \\
66.0)\end{array}$ \\
\hline Resources of ED not used & & $\begin{array}{l}133(53.4 \%)(\mathrm{Cl} 95=47.0 \text { to } \\
59.7)\end{array}$ \\
\hline Patients discharged & & $\begin{array}{l}179(71.9 \%)(\mathrm{Cl} 95=65.9 \text { to } \\
77.4)\end{array}$ \\
\hline $\begin{array}{l}\text { Medical prescription when } \\
\text { discharged }\end{array}$ & & $\begin{array}{l}111(44.6 \%)(\mathrm{Cl} 95=38.3 \text { to } \\
51.0)\end{array}$ \\
\hline Unnecessary† & & $\begin{array}{l}107(43.0 \%)(\mathrm{Cl} 95=37.7 \text { to } \\
49.4)\end{array}$ \\
\hline Main complaint & 249 & \\
\hline Respiratory symptoms & & $\begin{array}{l}65(26.1 \%)(C I 95=20.8 \text { to } \\
32.0)\end{array}$ \\
\hline Feeding problems & & $34(16.7 \%)(\mathrm{Cl} 95=9.7$ to 18.6$)$ \\
\hline Digestive symptoms & & $32(12.9 \%)(\mathrm{Cl} 95=9.0$ to 17.7$)$ \\
\hline Excessive crying & & $32(12.9 \%)(C I 95=9.0$ to 17.7$)$ \\
\hline Dermatologic symptoms & & $28(11.2 \%)(\mathrm{Cl} 95=7.6$ to 15.8$)$ \\
\hline Fever & & $25(10.0 \%)(\mathrm{Cl} 95=6.6$ to 14.5$)$ \\
\hline Other & & $33(13.3 \%)(\mathrm{Cl} 95=9.3$ to 18.1$)$ \\
\hline Diagnosis & 249 & \\
\hline Excessive worry & & $\begin{array}{l}51(20.5 \%)(\mathrm{Cl} 95=12.8 \text { to } \\
22.6)\end{array}$ \\
\hline Benign infectious diseases & & $\begin{array}{l}48(19.3 \%)(C \mid 95=14.5 \text { to } \\
24.7)\end{array}$ \\
\hline Severe infectious disease & & $\begin{array}{l}43(17.3 \%)(\mathrm{Cl} 95=12.8 \text { to } \\
22.6)\end{array}$ \\
\hline Digestive disorders & & $\begin{array}{l}40(16.1 \%)(C \mid 95=11.7 \text { to } \\
21.2)\end{array}$ \\
\hline Feeding problems & & $\begin{array}{l}22(8.8 \%)(C I 95=5.6 \text { to } \\
13.1)\end{array}$ \\
\hline Other & & $\begin{array}{l}45(18.8 \%)(C \mid 95=13.5 \text { to } \\
23.4)\end{array}$ \\
\hline $\begin{array}{l}\text { Distance between PED-home } \\
(\mathrm{km})\end{array}$ & 244 & $10.8(18.8) / 6.3(4.2$ to 11.0$)$ \\
\hline $\begin{array}{l}\text { ED as the first contact with a } \\
\text { paediatrician }\end{array}$ & 249 & $\begin{array}{l}145(58.2 \%)(\mathrm{Cl} 95=51.9 \text { to } \\
64.4)\end{array}$ \\
\hline $\begin{array}{l}\text { Parents not informed at the } \\
\text { maternity ward } \neq\end{array}$ & 249 & $\begin{array}{l}115(46.2 \%)(\mathrm{Cl} 95=39.9 \text { to } \\
52.6)\end{array}$ \\
\hline
\end{tabular}

Values a presented as $\mathrm{n}(\%)(95 \% \mathrm{Cl})$, mean (SD), median (Q1; Q3). ${ }^{*}$ On-call care services: ED visit during on-call care hours. †Unnecessary ED visit: newborn not referred; resources of PED not used.

$\ddagger$ Parents informed about the HAS recommendations at the maternity ward.

ED, emergency department; HAS, Haute Autorité de Santé; PED, paediatric emergency department.

\section{Procedures}

Two interviews were carried out after the PED visit. These interviews were performed by two trained clinical researchers of the Department of Clinical Research and Innovation of Nice University Hospital (MI and DD). The first interview took place 2-7 days after the visit to the PED to collect the data concerning the newborn, the parents and any medical or paramedical consultations carried out (questionnaire 1) (online supplemental appendix 2). The second interview took place within a week after the newborn's first month of life. This interview focused on any other medical consultations since the first telephone interview to establish the child's complete care pathway (questionnaire 2) (online supplemental appendix 3).

The patients were considered as 'lost to follow-up' if the parents could not be reached during the telephone interviews. The parents were called three times at different times of the day if they did not pick up, and this was repeated once in 48 hours (ie, a maximum of six attempts to call).

\section{Statistical analysis}

Continuous variables are expressed as a mean (SD) and median (first and third quartile). Categorical variables are expressed as percentages with a 95\% CI. The $\chi^{2}$ test and Fisher's exact test (when size $<10$ ) were used to compare the percentages. The Student's t-test and Mann-Whitney U-test were used to compare the means after checking the normality of the distributions. The effect sizes were calculated using the contingency coefficient for significant $\chi^{2}$ test and the Cohen statistic $d$ for a significant Student's t-test: 'weak' $(d=0.2-0.5)$, 'moderate' $(d=0.5-0.8)$ and 'strong' $(d>0.8){ }^{16}$

After describing the characteristics of the newborns according to the care pathway and then the PED consultation, we carried out two multivariate logistic regression analyses to estimate the risk factors associated with a noncompliant care pathway with the HAS recommendations (model 1) and an unnecessary visit to the PED (model 2 ). The modelling of categorical variables was studied using the likelihood ratio test. The selection of predictor variables was performed using a bottom-up, step-by-step procedure. Model 1 was adjusted for gender while model 2 was adjusted for gender and age at the time of the PED visit.

The fit of the regression model was assessed using the Hosmer-Lemeshow test $(\mathrm{p}=0.484$ and $\mathrm{p}=0.695$, respectively). ORs are expressed with a $95 \%$ CI.

The significance level $p$ was fixed at 0.05 . All statistical analyses were performed using STATA V.10.0 and R Studio V.3.2.2 for Macintosh.

\section{Patient and public involvement}

There was no patient or public involvement in the design of this protocol.

\section{RESULTS}

During the study period, 510 newborns attended our PED. Among these, 230 patients were not included in the study and a further 31 were excluded from analysis (figure 1). 
Table 4 Risk factors associated with a non-compliant care pathway

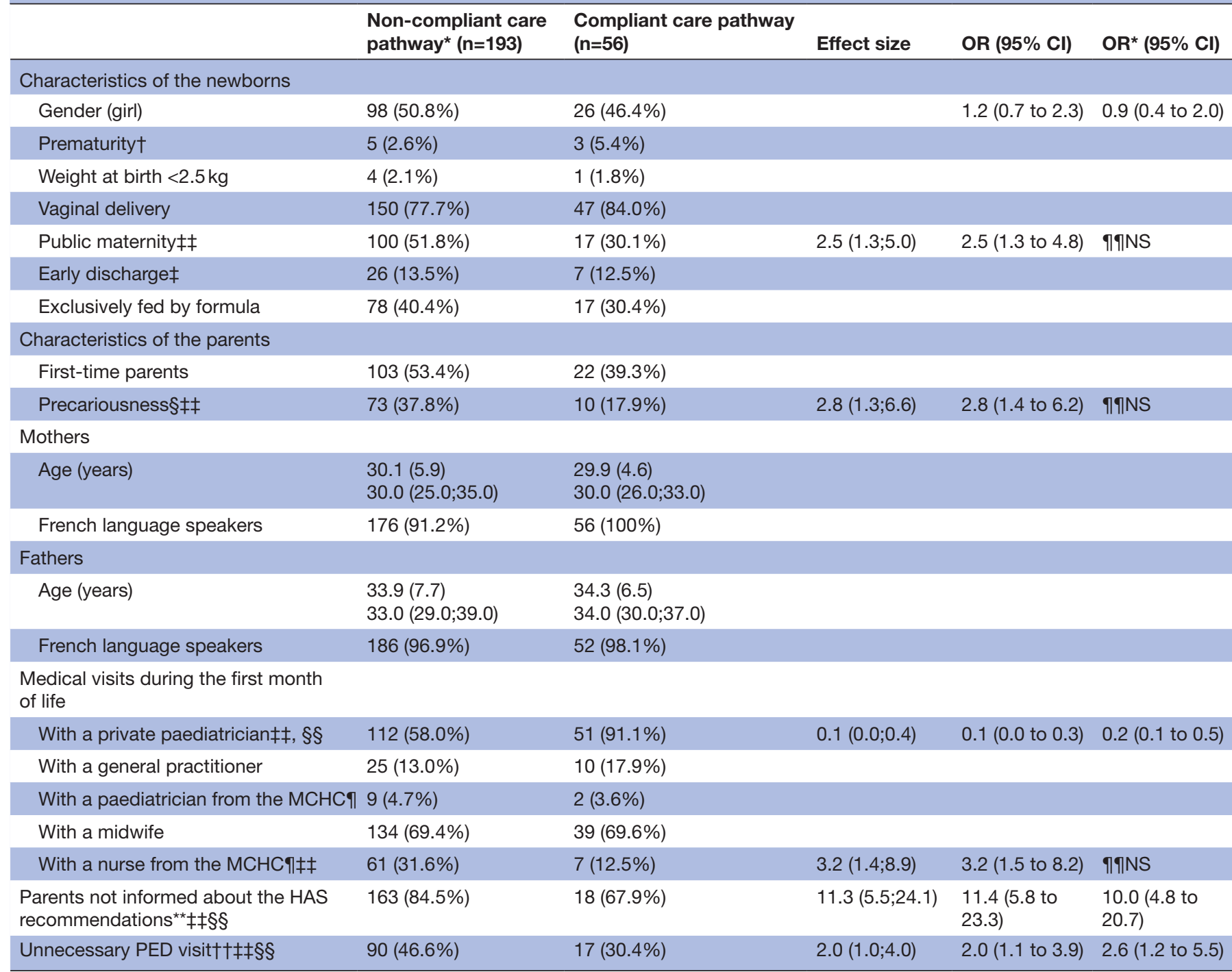

Values are presented as $\mathrm{n}(\%)(95 \% \mathrm{Cl})$, mean (SD), median (Q1; Q3); risk factors are presented in univariate analysis as OR (95\% Cl) and in multivariate analysis as adjusted OR, ORa $(95 \% \mathrm{Cl})$.

${ }^{*}$ Non-compliant care pathway: the medical consultation with a paediatrician (or a general practitioner) not carried out between 6 and 10 days of age according to the HAS recommendations.

†Prematurity: $<37$ weeks of pregnancy.

$\ddagger$ Early discharge: discharge from the maternity ward $<3$ days if vaginal delivery, $<4$ days if caesarean.

§Precariousness: EPICES score $>30$.

IMCHC: Maternal and child healthcare services.

**Parents informed about the HAS recommendations at the maternity ward.

††Unnecessary PED visit: newborn not referred; resources of PED not used.

$\ddagger \ddagger P<0.05$ in univariate analysis.

$\S \S \mathrm{P}<0.05$ in multivariate analysis

ๆๆNS: not significative in multivariate analysis.

HAS, Haute Autorité de Santé; PED, paediatric emergency department.

Therefore, 249 newborns were included in the final analysis. The gender distribution of the 249 newborns was well balanced ( $49.8 \%$ female). The population characteristics can be found in table 1 .

Overall, the care pathways for 193 newborns (77.5\%) were non-compliant with the HAS's postbirth follow-up recommendations (ie, no medical consultation between 6 and 10 days of age) and $55(22.1 \%)$ did not receive any medical follow-up during their first month of life (table 2). One hundred and seventy-three newborns $(69.5 \%)$ were followed by a midwife. Only $68(27.3 \%)$ of the parents reported having received correct information on discharge from the maternity ward about consulting a paediatrician or general practitioner between 6 and 10 days of age.

The PED visit was unnecessary in $43.0 \%$ (107 patients) of the cases (table 3). The main reason retained for the visit was 'Excessive worry' (20.5\%). 
Table 5 Risk factors associated with unnecessary visit to PED

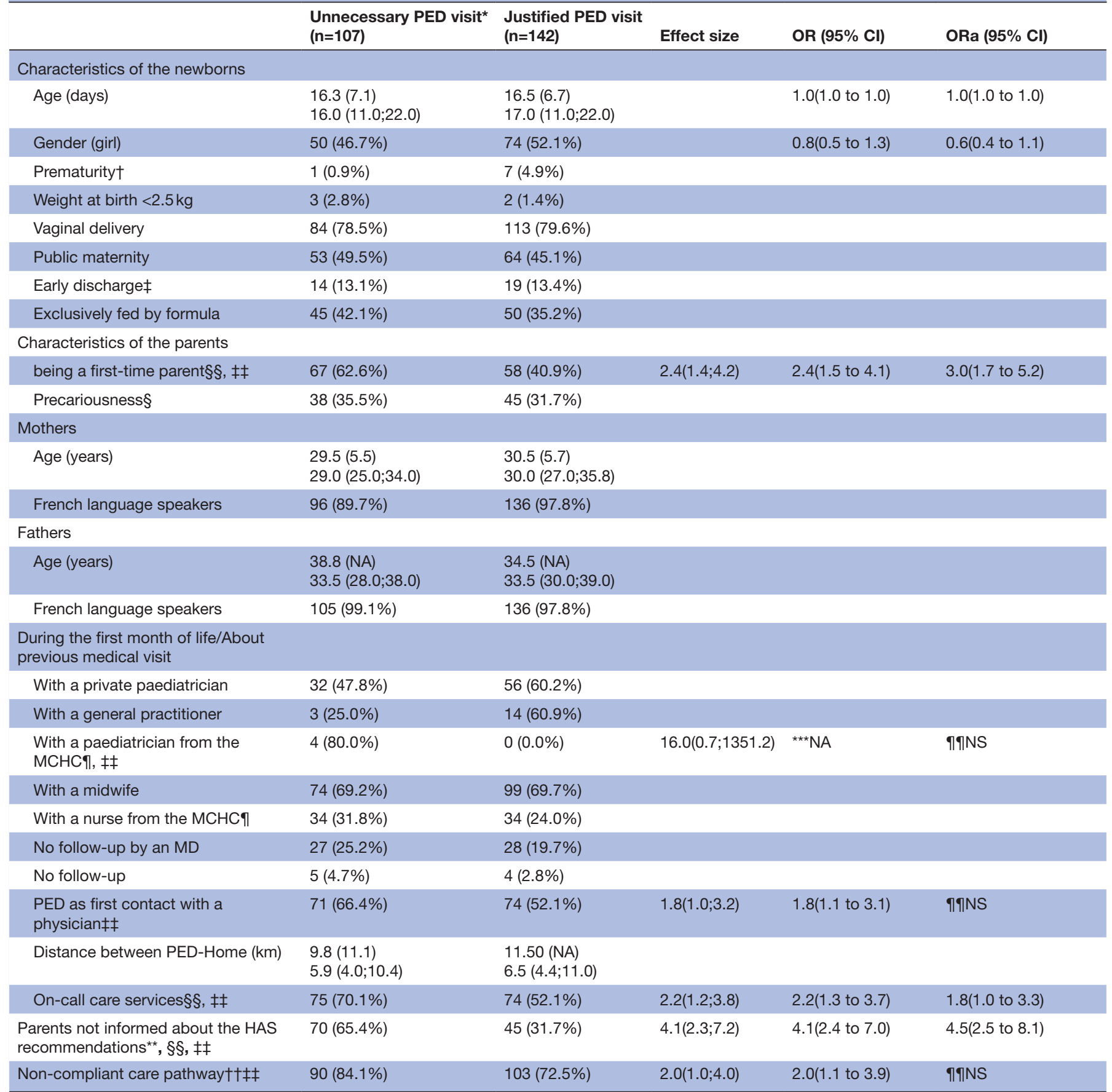

Values are presented as $\mathrm{n}(\%)(95 \% \mathrm{Cl})$, median (Q1; Q3); risk factors are presented in univariate analysis as OR (95\% Cl) and in multivariate analysis as adjusted OR, ORa $(95 \% \mathrm{Cl})$.

*Unnecessary PED visit: newborn not referred; resources of PED not used.

†Prematurity: $<37$ weeks of pregnancy.

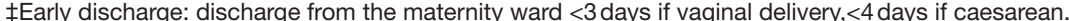

§Precariousness: EPICES score $>30$.

१MCHC: maternal and child healthcare.

${ }^{* *}$ Parents informed about the HAS recommendations at the maternity ward.

††Non-compliant care pathway: the medical consultation not carried out with a paediatrician (or a general practitioner) between 6 and 10 days of age according the HAS recommendations.

$\pm \pm \mathrm{P}<0.05$ in univariate analysis

$\S \S \mathrm{P}<0.05$ in multivariate analysis.

ๆ⿻NS: not significant in multivariate analysis.

${ }_{* * \star N A}$ not applicable in univariate analysis because size $\mathrm{n}=11$.

HAS, Haute Autorité de Santé; PED, paediatric emergency department. 
In multivariate regression analysis (model 1 , table 4), only an unnecessary visit and lack of information were significantly associated with a care pathway that is noncompliant with the follow-up recommendations with an adjusted OR of 2.6 (95\% CI 1.2 to $5.5 ; \mathrm{p}=0.016)$ and 10.0 (95\% CI 4.8 to $20.7 ; \mathrm{p}<0.001$ ), respectively. Follow-up by a private paediatrician was significantly associated with a compliant care pathway with an adjusted OR of $0.2(95 \%$ CI 0.1 to $0.5 ; p=0.001$ ). A visit to the PED during on-call care hours, being a first-time parent, and lack of information (model 2, table 5) were significantly associated with an unnecessary visit with an adjusted OR of 1.8 (95\% CI 1.0 to $3.3 ; \mathrm{p}=0.039$ ), 3.0 (95\% CI 1.7 to $5.2 ; \mathrm{p}=0.001)$ and 4.5 (95\% CI 2.5 to $8.1 ; \mathrm{p}=0.001)$, respectively.

\section{DISCUSSION}

This study was the first to analyse the care pathway for newborns admitted to a PED according to the French recommendations introduced in 2014. Only $22.5 \%$ of the newborns analysed in the study had a compliant care pathway which was a factor contributing to a justified visit to the PED. Conversely, newborns with a non-compliant care pathway were more likely to have an unnecessary visit to the PED. It would, therefore, seem that a medical consultation between 6 and 10 days of age avoids unnecessary and visits to PEDs. Gazmararian et $a l^{17}$ reported the general practitioner or the paediatrician are the most reliable sources of information for mothers. If the paediatrician is seen later after discharge from the maternity ward, EDs tend to be a substitute for this source of information: according to our results the first medical contact after leaving the maternity ward was the paediatrician of the PED for 145 newborns (58.2\%).

Our study suggests that the main barrier for compliance with the national follow-up recommendations for newborns, lies in the quality of the information about the care pathway provided to the parents in the maternity ward: $46.2 \%$ of the parents felt they had not received enough information. An information sheet reminding the parents to consult for a first medical visit (online supplemental appendix 1) was given to all parents on discharge from the maternity ward. However, a study by Schimmel $e a^{18}$ suggests that parental adherence to postnatal recommendations is better if explained orally and not just in writing.

Although a follow-up by a paediatric practitioner emerged as a significant factor in the compliant care pathway, in France the parents can also consult at a maternal and child healthcare centre, especially in specific situations such as preterm birth, low birth weight, twin birth or social difficulties when detected during the pregnancy or the maternity ward stay. However, getting an appointment in time, whether with a paediatric nurse or a doctor, is often not possible which means that the recommended time window for the first medical visit (age 6-10 days) cannot be respected.
In our study, $69.5 \%$ of the newborns had a first consultation with a midwife at 6 days of age on average. However, this does not meet the care pathway criterion defined by the HAS recommendations which stipulate that a paediatrician or general practitioner with expertise in paediatrics must be seen. We cannot, therefore, draw a conclusion about this point.

Moreover, only precariousness emerged as a risk factor for a non-compliant care pathway. This is similar to an adult population for whom it is known that precariousness constitutes a risk of disruption in the care pathway. ${ }^{19-21}$

While few studies have described the care pathway for newborns, many authors have focused on newborns attending a PED. In our study, the PED visit was unnecessary in $43 \%$ of the cases that is close to the prevalence found in the literature $(45.3 \%-52.4 \%) .^{6-8}$

'Excessive worry' was retained as the main reason for $20.5 \%$ of consultations. In addition, about half $(44.6 \%)$ of the consultations ended with simple childcare advice without any medical prescription. This supports the notion that parental education can help prevent unnecessary visits to the ED. ${ }^{22-24}$

Our results are aligned with those from a study by Flanagan and Stewart ${ }^{2}$ regarding visits during on-call care hours in that consultation during working days is associated with an increased risk of hospitalisation. Claudet et $a l^{14}$ also reported that a low-severity reason for consultation was a risk factor for consulting at night. Unlike other studies we did not find that risk factors (such as a mother aged under 25 years and a newborn under 15 days), or protective factors (such as preterm birth), ${ }^{6-8}$ were significant.

Several limitations to our study deserve to be mentioned. To eliminate the bias influenced by our local healthcare network and consequently render our results more generalisable to other settings in France, it would have been interesting to compare our data with several French cities. In addition, a study carried out on all newborns, rather than those consulting at a PED, would provide a more comprehensive view of the care process. Furthermore, the absence of a control group in our study does not allow us to compare the care pathway set up by paediatricians (or general practitioners with an expertise in newborn follow-up). During our study period, the newborns attending the PED only represented $12 \%$ of all births registered in Nice and its surroundings.

However, standardised questionnaires completed by trained interviewers enabled optimal and comprehensive data collection. The response rate was acceptable $(88.9 \%)$ and the data was not interpreted until all the questionnaires were completed, thus avoiding bias.

In our study, while we used intervention as proof that the visit to the PED was justified, this alone is not sufficient to distinguish between a justified and non-justified visit as physicians may undertake unnecessary workups to alleviate parental anxiety, for example.

Finally, 149 children $(29.2 \%)$ potentially meeting the inclusion criteria were not included probably due to the workload 
and the organisation of medical and paramedical teams. However, according to our records, their profiles did not differ from those who were included in terms of gender, age, resource utilisation.

\section{CONCLUSION}

The newborn care pathway recommended by the HAS in 2014 seems to be difficult to apply. However, postbirth follow-up may lead to decrease unnecessary ED visits. A medical consultation with a paediatrician between 6 and 10 days is an essential element in the care pathway. Several areas for improvement could be proposed: the monitoring of the newborn should be anticipated and discussed with the parents before giving birth (prenatal consultations, childbirth preparation meetings), a hospital consultation could be offered for particular situations (social difficulties) and finally the follow-up consultation between 6 and 10 days of age, if not performed by a doctor, could be provided by a midwife.

\section{Author affiliations}

${ }^{1}$ Paediatric Emergency Department, Hôpitaux Pédiatriques de Nice CHU-LENVAL,

Nice, Provence-Alpes-Côte d'Azur, France

${ }^{2}$ Medical School, Université Côte d'Azur, Nice, France

${ }^{3}$ Equipe de Recherche EA 3279 - Centre d'Études et de Recherche sur les Services de Santé et la Qualité de Vie, Aix-Marseille Université, Marseille, France

${ }^{4}$ School of computing, University of Eastern Finland, Joensuu, Pohjois-Karjala,

Finland

${ }^{5}$ Neonatology, Centre Hospitalier Universitaire de Nice, Nice, Provence-Alpes-Côte d'Azur, France

${ }^{6}$ Paediatric Department, Princess Grace Hospital Centre, Monaco

${ }^{7}$ Department of Clinical Research and Innovation, Centre Hospitalier Universitaire de Nice, Nice, Provence-Alpes-Côte d'Azur, France

${ }^{8}$ Department of Public Health, Centre Hospitalier Universitaire de Nice, Nice, Provence-Alpes-Côte d'Azur, France

Contributors AT was responsible for protocol development, analyses, writing of the paper and the main author of the paper. A-LH was responsible for protocol development and supervised the analyses, writing of the paper. MI supervised the protocol development, data collection, writing of the paper, conducted the interviews. PV assisted in analyses, supervised the writing of the paper and had a main contribution to the editing of the paper. A-MM was responsible for protocol development and supervised the writing of the paper. $\mathrm{HH}$ supervised the protocol development, writing of the paper. DD was responsible for the data collection, supervised the protocol development and conducted the interviews. EF supervised the writing of the paper. CP supervised the protocol development, analyses and writing of the paper. SG supervised the protocol development, analyses and writing of the paper.

Funding The authors have not declared a specific grant for this research from any funding agency in the public, commercial or not-for-profit sectors.

Competing interests None declared.

Patient consent for publication Not applicable.

Ethics approval This study and was approved by Clinical Research Ethics Committee of the University Hospital Centre of Nice No 16-HPNCL-04.

Provenance and peer review Not commissioned; externally peer reviewed.

Data availability statement Data are available on reasonable request.

Supplemental material This content has been supplied by the author(s). It has not been vetted by BMJ Publishing Group Limited (BMJ) and may not have been peer-reviewed. Any opinions or recommendations discussed are solely those of the author(s) and are not endorsed by BMJ. BMJ disclaims all liability and responsibility arising from any reliance placed on the content. Where the content includes any translated material, BMJ does not warrant the accuracy and reliability of the translations (including but not limited to local regulations, clinical guidelines, terminology, drug names and drug dosages), and is not responsible for any error and/or omissions arising from translation and adaptation or otherwise.

Open access This is an open access article distributed in accordance with the Creative Commons Attribution Non Commercial (CC BY-NC 4.0) license, which permits others to distribute, remix, adapt, build upon this work non-commercially, and license their derivative works on different terms, provided the original work is properly cited, appropriate credit is given, any changes made indicated, and the use is non-commercial. See: http://creativecommons.org/licenses/by-nc/4.0/.

ORCID iDs

Antoine Tran http://orcid.org/0000-0002-1836-2742

Stéphanie Gentile http://orcid.org/0000-0003-3858-9503

\section{REFERENCES}

1 Lee HC, Bardach NS, Maselli JH, et al. Emergency department visits in the neonatal period in the United States. Pediatr Emerg Care 2014;30:315-8.

2 Flanagan CF, Stewart M. Factors associated with early neonatal attendance to a paediatric emergency department. Arch Dis Child 2014;99:239-43.

3 Calado CS, Pereira AG, Santos VN, et al. What brings newborns to the emergency department? Pediatr Emerg Care 2009;25:244-8.

4 Fernández Ruiz C. [Neonatal management in the emergency department of a tertiary children's hospital]. An Pediatr Barc 2003;65:123-8.

5 Ung S, Woolfenden S, Holdgate A, et al. Neonatal presentations to a mixed emergency department. J Paediatr Child Health 2007;43:25-8.

6 Batu ED, Yeni S, Teksam O. The factors affecting neonatal presentations to the pediatric emergency department. J Emerg Med 2015;48:542-7.

7 Richier P, Gocko X, Mory O, et al. [An epidemiological study of early consultations of newborns in pediatric emergency units]. Arch Pediatr 2015;22:135-40.

8 Kennedy TJT, Purcell LK, LeBlanc JC, et al. Emergency department use by infants less than 14 days of age. Pediatr Emerg Care 2004;20:437-42.

9 Meara E, Kotagal UR, Atherton HD, et al. Impact of early newborn discharge legislation and early follow-up visits on infant outcomes in a state Medicaid population. Pediatrics 2004;113:1619-27.

10 Coulm B, Blondel B. [Hospital length-of-stay after childbirth in France]. J Gynecol Obstet Biol Reprod 2013;42:76-85.

11 Blondel B, Lelong N, Kermarrec M. [Trends in perinatal health in France between 1995 and 2010: Results from the National Perinatal Surveys]. J Gynecol Obstet Biol Reprod 2012;41:151-66.

12 Haute Autorité de Santé. Sortie de maternité après accouchement : conditions et organisation du retour domicile des mères et de leurs nouveau-nés. Available: https://www.has-sante.fr/jcms/c 1290110/fr/sortie-de-maternite-apres-accouchement-conditions-etorganisation-du-retour-a-domicile-des-meres-et-de-leurs-nouveaunes [Accessed 03 Jun 2021].

13 Ressources retour domicile - Réseau PerinatMed [Internet]. Available: https://www.reseauperinatmed.fr/CMS/News/92 [Accessed 04 Aug 2021].

14 Claudet I, De Montis P, Debuisson C, et al. [Analysis of neonate admissions to the pediatric emergency department]. Arch Pediatr 2012;19:900-6.

15 Labbe E, Blanquet M, Gerbaud L, et al. A new reliable index to measure individual deprivation: the EPICES score. Eur J Public Health 2015;25:604-9.

16 Fritz CO, Morris PE, Richler JJ. Effect size estimates: current use, calculations, and interpretation. J Exp Psychol 2012;141:2-18.

17 Gazmararian JA, Dalmida SG, Merino Y, et al. What new mothers need to know: perspectives from women and providers in Georgia. Matern Child Health J 2014;18:839-51.

18 Schimmel MS, Wasserteil N, Perry ZH, et al. Parents' compliance with specific medical instructions in newborn discharge letters. Paediatr Child Health 2010;15:649-53.

19 Steffen M. Universalism, Responsiveness, Sustainability--Regulating the French Health Care System. N Engl J Med 2016;374:401-5.

20 Schor EL, American Academy of Pediatrics Task Force on the Family. Family pediatrics: report of the task force on the family. Pediatrics 2003;111:1541-71.

21 Benoit J, Berdah L, Carlier-Gonod A, et al. [Ethics in pediatric emergencies: Care access, communication, and confidentiality]. Arch Pediatr 2015;22:554-61.

22 Mangione-Smith R, DeCristofaro AH, Setodji CM, et al. The quality of ambulatory care delivered to children in the United States. N Engl J Med 2007;357:1515-23. 
23 Ohns MJ, Oliver-McNeil S, Nantais-Smith LM, et al. Nonurgent Use of the Emergency Department by Pediatric Patients: A TheoryGuided Approach for Primary and Acute Care Pediatric Nurse Practitioners. J Pediatr Health Care 2016;30:339-46.
24 Doobinin KA, Heidt-Davis PE, Gross TK, et al. Nonurgent pediatric emergency department visits: Care-seeking behavior and parental knowledge of insurance. Pediatr Emerg Care 2003;19:10-14. 